\title{
Problems and Guarantee Mechanism of Dynamic Matching Between Modern Service Industry and Advanced Manufacturing Industry in Heilongjiang
}

\author{
Wenwu Yu
}

Yangzhou Polytechnic Institute, business school, Yangzhou 225127, China

Email:wwy790629@126.com

\begin{abstract}
ABSRTACT
Dynamic matching development refers to the phenomenon that two systems influence each other through various interactions. Two industrial subsystems influence each other through their respective supply and demand elements, the dynamic matching degree reflects the degree of their coordinated development. Dynamic matching development is a complete social systems engineering, is a two-way interactive causal relationship, is dominated by one side due to demand or supply factors, forming a relationship of mutual promotion and common development; At the same time, the government's policy and the macroeconomic regulation guide the development scale and direction of modern service industry and advanced manufacturing industry, and promote the optimization of industrial structure and the formation of scale effect. On the basis of expounding the problems existing in the dynamic matching of modern service industry and advanced manufacturing industry in Heilongjiang, this paper puts forward the guarantee mechanism of the dynamic matching of the two industries.
\end{abstract}

Keywords: modern service industry, advanced manufacturing industry, dynamic matching, safeguard mechanism

\section{INTRODUCTION}

At present, the industrial structure of the world's major developed countries has shown a general trend of transition from "industrial economy" to "service economy" . In the age of the Internet, "cross-border" is the trend. In recent years, the cross-border integration of producer services and manufacturing is becoming more and more obvious, which has become a new trend to accelerate the development of producer services. On the one hand, the trend of service-oriented manufacturing has been further strengthened, and many manufacturing enterprises in the fields of transportation, electrical, equipment manufacturing, etc. have continued to spin off their manufacturing links and shift their business focus to the service links. On the other hand, the productive service industry and the manufacturing industry are developing in a cross-organizational way. The service subcontracting, the crowd-sourcing mode and the innovative business mode emerge one after another. At the same time, with the increasing specialization of the social division of labour, the producer services, which cover a wide range of fields such as finance, R \& D, Logistics and information, have gradually been separated from the manufacturing industry, it has become a key link to promote the progress of industrial technology, support the transformation and upgrading of industrial structure and innovation.
This study proposes that the coupling development of supply and demand of producer services and manufacturing industries is reflected in the separation of specialization and the fusion of differentiation-driven advantages, and they have a symbiotic co-evolution system, there are self-organization evolution of independent secondary system, coupling and balance of supply and demand system structure, and influence of environment and other subsystems, the coupling effect of the two is more complicated than understood now.

\section{PROBLEMS IN DYNAMIC MATCHING BETWEEN MODERN SERVICE INDUSTRY AND ADVANCED MANUFACTURING INDUSTRY IN HEILONGJIANG}

\subsection{The dynamic matching development of modern service industry and advanced manufacturing industry is indirect}

The development of modern services in Heilongjiang is relatively separate and independent from that of advanced manufacturing. The low-end manufacturing in advanced manufacturing has resulted in slow demand and intelligent transformation, poor supply of effective services and 
inefficient allocation of supply and demand, the corresponding dynamic development platform of the industry is relatively deficient, which leads to difficulties in information transmission and communication, resources cannot be shared, and the third-party intermediary is poorly regulated, resulting in low efficiency, unable to promote the dynamic coordinated development of the two, and low efficiency in resource allocation, mismatch of supply and demand.

\subsection{The industrial structure of the modern service industry and the advanced manufacturing industry is irrational}

On the one hand, the advanced manufacturing industry is dominated by the middle and low-end industries, while the high-end industries are few, the productive service links from technological research and development to marketing and sales are all digested within the enterprise, and the reluctance to outsource or poor awareness of outsourcing not only increases the cost of the enterprise, but also affects the overall strength and competitiveness of the advanced manufacturing industry, on the other hand, the modern service industry is still dominated by the traditional service industry, the development of knowledge-intensive industries is slow, and the size of enterprises is small, and the quality of products provided is not high, it restricts the development of the advanced manufacturing industry seriously, leads to the single product and weak product development ability of the advanced manufacturing industry, and finally cannot meet the requirements of the two industries dynamic matching development.

\subsection{The mode of coordinated development of the two industries is not perfect}

Due to the respective shortcomings between the two industries, such as the serious homogenization of modern service enterprises, the lack of core technology, and the low service capacity, at the same time, the incomplete industrial chain of the advanced manufacturing industry, the incompact industrial connection and the weak supporting capacity of the industry restrict the effective development of the modern service industry, however, modern service enterprises provide more single service function or a key link of production and management to advanced manufacturing enterprises, and the resources are not maximized, so the two industries are basically "pointto-point" or "point-to-group" coordinated development model, is not the best "group-to-group" coordinated development model.

\subsection{The service lag of modern service industry to advanced manufacturing industry}

Mainly because of its own underdevelopment, such as technological progress and the lack of high-quality workers, the overall small size and technological backwardness of Heilongjiang's modern service industry, there are some common problems in enterprises, such as low degree of aggregation, few types of business and poor quality of service. At the same time, in the empirical analysis, the Granger causality method is used to analyze the dynamic matching development relationship between the two, which restricts the coordinated development of modern service industry and advanced manufacturing industry.

\subsection{The role of advanced manufacturing in modern services is limited}

Heilongjiang's manufacturing sector is still dominated by low value-added industries, while the proportion of high value-added industries is small, and many enterprises still adopt the traditional mode of production and development, being in the middle of the value chain, and being in the upper and lower reaches of the industrial chain, there are fewer high-tech products such as R \& D, marketing, and so on. Manufacturing enterprises have less demand for modern service industries, and their pulling effect on modern service industries is limited, leading to the financial industry, Information Technology, scientific research and other industries less impetus. In addition, the demand for outsourcing services of manufacturing enterprises is insufficient, because some enterprises do not trust outsourcing companies and are more willing to increase the cost of enterprises to complete $R \& D$, marketing and other links within enterprises, and some enterprises have poor awareness of outsourcing services, the slow development of service outsourcing has restricted the demand and development of productive service in manufacturing enterprises.

\subsection{Unbalanced regional development and low radiation effect}

Due to the level of regional economic development in Heilongjiang, geographical location, resource advantages and other reasons, resulting in uneven regional development, the most comprehensive strength of Harbin, the agglomeration of many producer service enterprises and manufacturing enterprises leads to the irrational regional distribution of modern service industries and advanced manufacturing industries, and the small scale of the two industries 'development makes it difficult to form scale effect, it is also more difficult to achieve the radiation effect on the surrounding areas of the two industries, the two industries have also had a certain impact on the development of agglomeration. 


\section{THE DYNAMIC MATCHING MECHANISM BETWEEN MODERN SERVICE INDUSTRY AND ADVANCED MANUFACTUING INDUSTRY IN HEILONGJIANG}

\subsection{Set up the market-oriented mechanism of modern service industry}

Open up new markets such as information exchange and consultation market, technology exchange market, education and training market To change the bad phenomena such as serious monopoly and high threshold of entry in some industries of modern service industry in Heilongjiang, to establish a scientific and reasonable mechanism of industry entry, and to simplify the process and improve the efficiency of work; Encourage non-stateowned enterprises to enter into the productive service sector, provide preferential policies and expand the scale of the industry; vigorously develop service outsourcing, with particular emphasis on the development of information technology outsourcing, and vigorously develop the financial sector, we will establish a financial circle with Harbin as the center, improve the mechanism of self-regulation of industries and the system of productive services, establish a public service platform and improve the quality and efficiency of services, and increase government expenditure on modern services, we will continue to formulate relevant incentive policies conducive to the development of modern service industries.

\subsection{Build a platform carrier for the integrated development of advanced manufacturing and modern service industries}

Depending on the advantages, a cluster of industrial chain with modern service function is built to promote the two industries to cooperate with each other, match the service level and structure, and improve the degree of industrial relevance. Within the industrial cluster, a comprehensive service platform including information consultation, financial insurance, technological research and Development, scientific research, trademark and patent, etc. shall be established, and a central regional service system shall be established to realize the sharing of information and resources, development trend of symbiosis and integration between modern service industry and advanced manufacturing industry.

\subsection{Strengthen communication between modern service industry and advanced manufacturing industry}

Communication can be enhanced by creating a platform. First, create a credit platform to assess the credit ratings of Heilongjiang companies and publish their credit rankings. Then, create an information-sharing platform to distribute information about all companies on the platform, to save enterprises 'time in searching for information and to find enterprises that need communication or cooperation more quickly; finally, to establish a special service platform to classify the enterprises in the modern service industry, it is helpful for manufacturing enterprises to find the corresponding service enterprises quickly and accurately when they need a certain link of productive service, which also improves the efficiency of communication between enterprises.

\subsection{Establish a mechanism for distributing benefits}

First, the principle of distribution of benefits must be determined. To find leaders in the two industries and leaders at the managerial level of large, medium and small enterprises, and to discuss and determine the principles and rules for the distribution of benefits based on fairness and justice in the two industries, and the principle of public timing as well as the distribution of interests rules, to be recognized by the industry, Flexible Cooperation Mechanism; Second, the establishment of integrity mechanism. In the process of dynamic matching between modern service industry and Manufacturing Industry, we should supervise and evaluate the rationality of the benefit distribution mechanism of both sides. To some extent, integrity can be blacklisted to ensure the integrity of both sides, and reliability provides a solid basis for the best relationship between the two industries.

\subsection{Establish risk control mechanisms}

To formulate a set of complete strategies on how to prevent, identify, evade and control risks so as to minimize the losses caused by possible risks, and in the course of the dynamic matching development of the two industries, must Anticipate the risk in advance, avoids the risk as far as possible, also must consider and formulates if the risk post-processing method.

\subsection{Establish a talent development mechanism}

First, we should establish a talent-training mechanism that combines "production, study and research". Universities and research institutes should establish a cooperative relationship with enterprises so that they can set up relevant specialties for enterprises to train corresponding 
Manufacturing and Producer Services[J]. Structural Change and Economic Dynamics,2011,9(5) talents. Second, we should increase investment in education, finally, the two industries can bring in knowledge-based and professional talents through the establishment of various funds, or the government can bring in knowledge-based and professional talents through scientific research projects, projects, etc. , and by weakening the number of papers, project funds and other hard indicators, the establishment of a scientific and reasonable incentive system for talent.

\section{CONCLUSION}

Based on the above analysis, this paper puts forward some countermeasures and suggestions for the dynamic matching development of modern service industry and advanced manufacturing industry in Heilongjiang, in the light of the actual situation of Heilongjiang's economy and industrial transformation, industrial spatial distribution and regional cooperation, this paper starts with the operation of the mechanism, organization, system and policy, etc. , some suggestions are put forward, such as paying attention to the transformation of the innovation model, building the functional group model, promoting the dynamic matching development model of the integration group, perfecting the dynamic matching development cooperation mechanism between the advanced manufacturing industry and the modern service industry, and constructing the dynamic matching development supervision and evaluation system , so as to solve the problems of excess capacity of advanced manufacturing industry and the shortage of effective supply of modern service industry, realize the optimal allocation of factors, promote the growth of Total factor productivity, and promote the coordinated development of modern service industry and advanced manufacturing industry in Heilongjiang.

\section{REFERENCES}

[1] Czarnowski Z, Herzberger B. Do Direct R\&D

Subsidies Lead to the Monopolization of R\&D in the Economy[J]. ZEW Discussion,2012(3)

[2]P Guerrier, V Meliciani.Technology and International Competitiveness: The Interdependence between Manufacturing and Producer Services[J]. Structural Change and Economic Dynamics,2012(16)

[3] Yusuf, Shahid.Innovative East Asia: The Future of Growth[M]: Washington. World Bank,2011

[4] Tine J Manufacturing and Services: from Mass Production to Mass Customization[J]. Journal of Systems Science and Systems Engineering,2011,20(2)

[5] Paolo Valentina Technology and International Competitiveness: The Interdependence between 